\title{
Review
}

\section{Golf and Skin Health: A Narrative Review}

\author{
Allan G. Matthews ${ }^{1}$, Hannah Preston ${ }^{2}$ (D), Andrew Murray ${ }^{3,4,5}$, Roger Hawkes ${ }^{4,5}$ \\ ${ }^{1}$ Consultant Dermatologist, Queen Margaret Hospital, Dunfermline, Scotland \\ ${ }^{2}$ New Royal Infirmary Edinburgh, NHS Lothian, Scotland \\ ${ }^{3}$ Sports and Exercise, University of Edinburgh, Scotland \\ ${ }^{4}$ Golf and Health Project, Sponsored by the World Golf Foundation, USA \\ ${ }^{5}$ European Tour Performance Institute, England
}

\section{History: \\ Keywords: \\ Golf \\ Skin cancer \\ Sun exposure \\ Skin health \\ UVR}

Article Information

Received: May 30, 2018

Accepted: October 1, 2018

Published: October 31, 2018

\begin{abstract}
Objectives: Recent studies have reported that playing golf has overall physical and mental health benefits. Through being placed in the sun for extended periods of time, the golfing population faces an increased risk of ultraviolet radiation (UVR) associated skin problems, most importantly skin cancer. Our aim was to collate and summarise current literature on the relationship between golf and skin cancer.

Methods: We searched multiple web-based, health-focused databases (Medline, Embase, Cinahl, Web of science, Scopus, Sportdiscus, UK clinical trials, Current controlled trials and Prospero) to identify records. Relevant papers were critically appraised and reported using a descriptive analysis.

Results: A total of 11 studies are included in the review. Golf is associated with relatively more UVR exposure than other outdoor activities such as fishing, tennis, pool swimming, cricket, gardening, 'sun-worshipping' and sailing. Calculated relative risk of non- melanoma skin cancer, based on cumulative UV exposure, is higher in golfers than non-golfers. Mid morning tee-times or playing golf between $11 \mathrm{am}-3 \mathrm{pm}$ associated with highest UVR exposures. Golfers can be exposed to potentially harmful levels of UVR during play in winter at some latitudes. Vertex (scalp), shoulders, back, back of neck and posterior arms exposed to more UVR than front of body during play. Common golf attire is of limited value in protecting the neck. Targeted skin cancer skin cancer prevention and early detection campaigns are well received among the golfing population.

Conclusions: Overall, playing golf is associated with longevity and both physical and mental health benefits. Studies to date indicate that golfers (professionals > recreational players) are exposed to potentially harmful levels of UVR during play, but the true morbidity/mortality associated with this exposure is not known. Playing golf should be encouraged in all age groups, though golfers, the golf industry and policy makers should act to minimize the harmful effects of UVR exposure, and have they have ability to also be hugely influential on an important public health message.
\end{abstract}

\section{INTRODUCTION}

Exposure to ultraviolet radiation (UVR) is the most important environmental risk factor in the development of cutaneous melanoma and non-melanoma skin cancers (basal cell carcinoma (BCC) and squamous cell carcinoma (SCC)), rates of which have been steadily increasing worldwide over

*Correspondence: Hannah Preston, New Royal Infirmary Edinburgh, NHS Lothian, Scotland

E-mail address: hannahpreston91@gmail.com the last 40 years [1]. UVR can also cause painful sunburn reactions, skin pigment changes, accelerated skin ageing and eye disorders such as cataracts. Conversely, UVR has important health benefits. Exposure to ultraviolet-B (UVB) radiation stimulates vitamin-D production, which is essential for skeletal health and optimal immune function [2]. There is emerging evidence that UVR has beneficial effects on cardiovascular risk factors independently of Vitamin D [3]. Sunlight is also known to have mood-lifting effects [4].

Playing golf has overall physical and mental health benefits, $[5,6]$ however by being placed in the sun for extended periods of time, the golfing population face an increased risk terms of the Creative Commons Attribution License (http://creativecommons.org/licenses/by/4.0/), which permits unrestricted use, distribution, and reproduction in any medium, provided the original work is properly cited. 
of UVR associated skin problems, most importantly skin cancer. Literature pertaining specifically to skin problems encountered by the golfing population is varied in its focus and quality. The aim of this narrative review was to collate and summarise this literature.

\section{MATERIALS AND METHODS}

\section{Search Strategy}

The following health focused databases and search platforms were used to search for studies: Medline, Embase, Cinahl, Web of science, Scopus, Sportdiscus, UK clinical trials, Current controlled trials and Prospero.

\section{Eligibility criteria}

The following inclusion and exclusion criteria were utilized:

\section{a. Inclusion criteria}

- English language articles only

- All age groups and both sexes of participants

- Research undertaken in both professional and recreational golfers and golf spectators

- Research articles discussing any aspect of skin health and/or ultraviolet radiation exposure in context of golf

- Sources of information can include primary research studies, reviews (including but not limited to systematic reviews, scoping reviews, meta-analyses), guidelines, as well as grey literature to include unpublished and on-going trials, annual reports, dissertations, and conference proceedings.

- Research articles not limited by geographical location, language, research setting or date of research

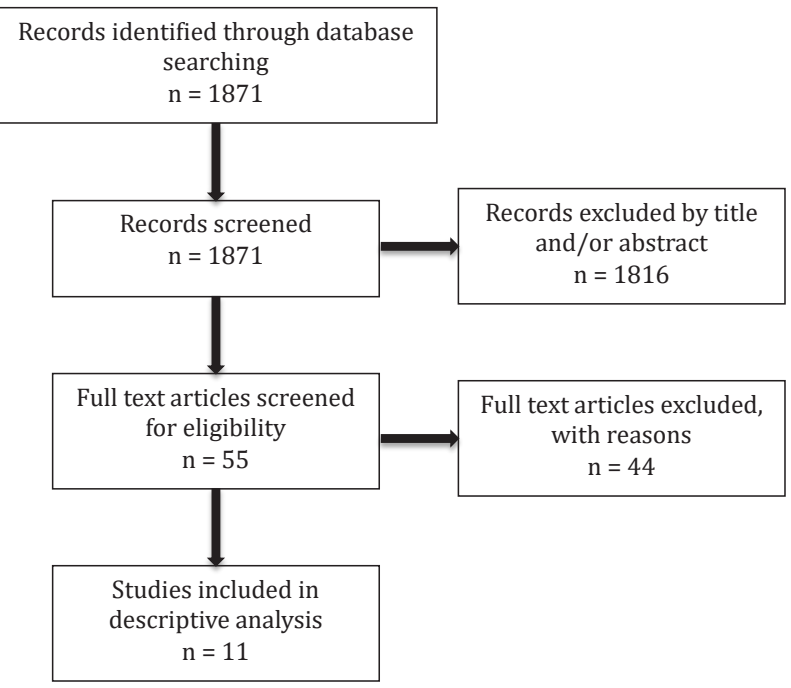

Figure 1. Prisma flow diagram

\section{b. Explicit exclusion criteria}

- Opinion pieces/ opinions, magazine and newspaper articles, case reports, papers with no data.

\section{Search Terms}

Each database was searched using the primary search term "golf". From this secondary search terms: "skin", "skin health", "skin cancer", "skin neoplasm", "melanoma", "basal cell carcinoma", "squamous cell carcinoma", "ultraviolet radiation", "sun”, "sunlight", "photoaging”, "Vitamin D” were used to narrow down eligible papers relating to golf and skin health. Two reviewers (AGM and HP) assessed the titles and abstracts applying the eligibility criteria. The same two reviewers appraised the selected papers. Additional studies were identified from the reference lists of included papers.

\section{Analysis}

A descriptive analysis was used to summarise the evidence collected.

\section{RESULTS}

The initial data search using the term 'golf' yielded a total of 1871 records. Review using the secondary terms of titles and/or abstracts excluded 1816 records, leaving 55 records to be assessed against our eligibility criteria. Critical appraisal of these records and review of their references identified a total of 11 studies relevant to our review that focused on golf and skin health (PRISMA flow diagram) (Figure 1).

\section{Method of study}

The majority of studies relating to golf and skin health focus on UVR dosimetry as their method of data collection [7-13]. Population- We identified one study that reports on skin cancer prevalence in female golfers, with the rest focusing on a male population [14].

\section{Sun protection practice}

There are two studies examining sun-protection practices in golfers/golf spectators $[15,16]$ highlighting that sun protection practice is generally poor, however education such as demonstrating current skin photo-damage has the ability to increase intention of taking up protective measures [12]. One study evaluates the feasibility and effectiveness of a targeted skin cancer prevention and an early detection campaign in golfers and golf-course workers [17], and also highlighted that a significant number of participants (99.3\%) after planned to improve their habits to sun exposure after this awareness was introduced. The back of the neck and wrist were found to have the highest UVR exposure [11,13]. Clothing is an important and easy tool in reducing UVR transmission, however common golfing attire is limited in protecting the back of the neck [10]. 
Table 1. Key Findings

\begin{tabular}{|c|c|c|}
\hline Author & Year & Descriptive Analysis \\
\hline $\begin{array}{l}\text { Holman CDJ et } \\
\text { al [7] }\end{array}$ & 1983 & $\begin{array}{l}\text { - Ultraviolet radiation (UVR) dosimetry field study carried out in Western Australia in Autumn } \\
\text { - Proportion of ambient UVR exposure at several anatomical sites investigated in five occupations and nine outdoor } \\
\text { recreational activities } \\
\text { - Both environmental and behavioural factors were of importance in determining overall levels of exposure and distri- } \\
\text { bution by site } \\
\text { - Golf associated with relatively more UVR exposure than fishing, tennis, pool swimming, cricket and gardening. }\end{array}$ \\
\hline $\begin{array}{l}\text { Hanke CW et al } \\
{[14]}\end{array}$ & 1985 & $\begin{array}{l}\text { - Study examining point-prevalence of skin cancer and potential risk factors in group of self-selected female golfers in } \\
\text { - USA } \\
\text { - } 51 \text { professional golfers and } 142 \text { amateur golfers evaluated } \\
\text { - Average age of } 28.4 \text { years (professionals) versus } 54.5 \text { years (amateurs) } \\
\text { - Based on number of years played and hours of golf per day, professionals exposed to } 5 x \text { more sunlight than amateurs } \\
\text { - No statistically significant difference in proportion of professional and amateur golfers with actinic keratosis (7/51 ver- } \\
\text { sus } 20 / 142 \text { ) or basal cell carcinoma (BCC) (4/51 versus } 11 / 142) \text {. } \\
\text { - Average age at diagnosis of BCC considerably less in professionals ( } 25.5 \text { years) versus amateurs (51.4 years) } \\
\text { - Likelihood of developing skin cancer related to eye and hair colour }\end{array}$ \\
\hline $\begin{array}{l}\text { Herlihy E et al } \\
{[8]}\end{array}$ & 1994 & $\begin{array}{l}\text { - UVR dosimetry field study carried out in Hobart, Tasmania in summer } 1991 \\
\text { - UVR exposure measured using UV dosimeters attached to seven anatomical sites, in } 94 \text { subjects engaged in } 6 \text { different } \\
\text { outdoor activities } \\
\text { - Concurrent behavioural and environmental observations made using diaries and monitoring station recorded ambient } \\
\text { UVR levels } \\
\text { - Tennis, sailing, and golf were the three activities that had the highest proportions of ambient UVR } \\
\text { - Time of day engaged in golf affected level of exposure - highest between } 11 \mathrm{am} \text { and 3pm }\end{array}$ \\
\hline $\begin{array}{l}\text { Thieden E et al } \\
\text { [9] }\end{array}$ & 2005 & $\begin{array}{l}\text { - UVR dosimetry study set in Denmark } \\
\text { - Subjects carried UVR dosimeter in wristwatch which measured continuously time-related UVR doses (in Standard } \\
\text { Erythema Doses }(\text { SEDs)*) } \\
\text { - Subjects also completed sun exposure behaviour diaries } \\
\text { - Estimated yearly UVR doses calculated based on personal and ambient measurement } \\
\text { - Subjects were } 285 \text { Danish volunteers with apparently healthy skin, including } 24 \text { adult amateur golfers from single golf } \\
\text { club. } \\
\text { - Daily erythemally effective UVR exposure ranged from } 0.7 \text { SED to } 3.7 \text { SED in golfers } \\
\text { - Golfers had the highest median percentage of the ambient UVR in the whole study population, which included "sun } \\
\text { worshippers" and gardeners. }\end{array}$ \\
\hline $\begin{array}{l}\text { Sung } \mathrm{H} \text { et al } \\
{[10]}\end{array}$ & 2006 & $\begin{array}{l}\text { - UVR dosimetry field study carried out in Midwestern USA in August and October } \\
\text { - Measurement of cumulative UVR exposure (measured as proportion of ambient UVR exposure) to specific body sites } \\
\text { in seven subjects during play (average } 4.5 \text { hours). } \\
\text { - Effects of clothing in reducing UVR exposure examined. } \\
\text { - Shoulders, back, back of neck and posterior arms were exposed to more UVR than the front of the body. } \\
\text { - Study showed the importance of clothing in reducing UVR transmission to skin. } \\
\text { - Common golf attire of limited value in protecting the back of neck. }\end{array}$ \\
\hline $\begin{array}{l}\text { Dixon HG et al } \\
\text { [15] }\end{array}$ & 2008 & $\begin{array}{l}\text { - Cross-sectional observational field survey of teenagers and adults at leisure during summer weekends between 11am } \\
\text { and 3pm in Melbourne, Australia from 1992-2002 } \\
\text { - Apparent decline in clothes cover among recreational golfers from 1992-2002. }\end{array}$ \\
\hline $\begin{array}{l}\text { Downs NJ et al } \\
\text { [11] }\end{array}$ & 2009 & $\begin{array}{l}\text { - UVR dosimetry field study set in Queensland, Australia } \\
\text { - UVR exposure measured using dosimeters placed on forearm, upper back and vertex of } 2 \text { golfers playing in the same } \\
\text { region, but under different atmospheric conditions, during a 7-month period extending from summer to winter. } \\
\text { - Subjects always played between } 1500 \text { and } 1730 \text { for } 2-2.5 \text { hours } \\
\text { - Both erythemal and vitamin D effective UVR exposure measured } \\
\text { - Non-melanoma skin cancer risk calculated using estimated cumulative annual UV exposure based on dosimeter read- } \\
\text { ings (numerous assumptions made) } \\
\text { - Calculated relative risk of non-melanoma skin significantly greater in persons playing a weekly round of golf com- } \\
\text { pared with office workers that do not play. } \\
\text { - At this latitude, golfers appear to be able to receive sufficient vitamin D effective exposures during play in winter. } \\
\text { - Greatest level of exposure recorded at vertex, then upper back (neck) }\end{array}$ \\
\hline $\begin{array}{l}\text { Perry A et al } \\
{[16]}\end{array}$ & 2010 & $\begin{array}{l}\text { - Study examining sun protection practices of golf event spectators, set in USA } \\
\text { - } 407 \text { subjects recruited to this questionnaire study (mostly middle-aged, white women) } \\
\text { - At baseline, self reported sun protection practices generally poor } \\
\text { - Demonstration of pre-existing 'photodamage' using a UV reflectance unit (non-validated tool) appeared to slightly } \\
\text { increase subject's level of intent to wear a hat and sunscreen in the future, but did not effect their perceived risk of skin } \\
\text { cancer. }\end{array}$ \\
\hline
\end{tabular}


Table 1. Key Findings (Continued)

\begin{tabular}{|c|c|c|}
\hline Author & Year & Descriptive Analysis \\
\hline $\begin{array}{l}\text { Downs NJ et al } \\
{[12]}\end{array}$ & 2011 & $\begin{array}{l}\text { - Study used global climatology and statistical modelling to estimate the relative risk of non-melanoma skin cancer for } \\
\text { weekly, single round competition golfers playing at different latitudes. } \\
\text { - Relative risk of NMSC was found to be proportional to golf tee time, with mid morning tee times generally presenting } \\
\text { the greatest risk in each latitude range. } \\
\text { - Golfers playing at lower latitudes have higher UVR exposure, thus an increased NMSC risk } \\
\text { - Study is limited by a number of assumptions including sky conditions, course geography, individual player clothing/ } \\
\text { behaviour and skin cancer risk factors aside form UVR exposure }\end{array}$ \\
\hline $\begin{array}{l}\text { Ysasi GG et al } \\
\text { [13] }\end{array}$ & 2014 & $\begin{array}{l}\text { - UVR dosimetry field study carried out in Spain during winter (January) } \\
\text { - Seven male players carried dosimeters on their caps and wrists during play across eight days (cloudless days only se- } \\
\text { lected) } \\
\text { - Play between hours of 10:00 and 15:00 (average } 4.5 \text { hours) } \\
\text { - UVR exposure higher at head position compared with wrist } \\
\text { - Mean daily UVR exposure was } 2.07 \text { SED in head position and } 1.62 \text { in wrist position } \\
\text { - At this latitude, golfers with skin types I \& II ** can be exposed to potentially harmful levels of UVR during play in } \\
\text { winter }\end{array}$ \\
\hline $\begin{array}{l}\text { Del Boz J et al } \\
{[17]}\end{array}$ & 2015 & $\begin{array}{l}\text { - Study examining feasibility and effectiveness of a targeted skin cancer prevention and early detection campaign in } \\
\text { golfers and golf-course workers. } \\
\text { - Study carried out across } 6 \text { golf clubs in Southern Spain in summer } \\
\text { - } 195 \text { recreational golfers and } 89 \text { outdoor golf-course workers had interview and skin examination } \\
\text { - Following examination and education, participants asked re intention to change behaviour } \\
\text { - A third of golfers reported at least one golf-related sunburn episode in the previous year } \\
\text { - On physical examination, lesions clinically suspicious for skin cancer (not histologically confirmed) identified in } \\
10.3 \% \text { of golfers and } 3.4 \% \text { of outdoor golf-course workers. Lesions identified clinically as actinic keratosis in } 40 \% \text { of } \\
\text { golfers and } 10.1 \% \text { of outdoor golf-course workers. } \\
\text { - Prevalence in age-matched controls in the same region was not reported } \\
\text { - The campaign rated positively by } 99.4 \% \text { of the participants; } 93.9 \% \text { stated that they intended to improve their sun expo- } \\
\text { sure habits and } 93.4 \% \text { said that they planned to examine their skin more frequently }\end{array}$ \\
\hline
\end{tabular}

${ }^{*}$ Standard Erythema Dose (SED) - a standardised measure of erythemogenic UV radiation.

$1 \mathrm{SED}$ is equivalent to an erythemal effective radiant exposure of $100 \mathrm{Jm}^{-2}$. The International Commission on Non-Ionising Radiation Protection has proposed UVR exposure limits depending on skin phototype.

** Fitzpatrick skin phototypes -

I - very sensitive, always burn, never tan, melano-comprimised

II - moderately sensitive, high risk of sunburn, achieve light tan, melano-compromised

III - moderately insensitive, moderate risk of sunburn, achieve medium tan, melano-competent

IV - insensitive, low risk of sunburn, achieve dark tan, melano-competent

$\mathrm{V}$ - insensitive, very low risk of sunburn, natural brown skin, melano-protected

VI - insensitive, extremely low risk of sunburn, natural black skin, melano-protected

\section{UVR exposure}

Papers that studied outdoor activities found that golf is associated with higher UVR exposure than other outdoor activities such as tennis, sailing and fishing which many people are aware of as a high UVR exposure activity, however the study also demonstrated that environmental and behaviour will determine overall exposure $[7,8]$. Golfing attire is not routinely tested for UVR transmittance. Professionals are exposed to higher UVR levels than amateurs, predominantly due to time on golf course, playing year-round and travelling to follow an temperate climate for practice and tournaments, therefore increasing overall high level UVR exposure. The key findings for each study are summarised in Table 1.

\section{DISCUSSION}

Golfers (both professional, amateur and caddies) can be exposed to potentially harmful levels of UVR during play and outdoor practice [7-14]. Golf is played all over the world, and the level of UVR to which an individual golfer's skin is exposed during play is dependent on a number of situational and personal variables including location of play (latitude \& altitude), season, tee time, duration of play, cloud cover, other weather conditions, facility factors (level of natural shade etc) and protective behavior (clothing choice and use of sunscreen) [18]. The use of sun protection practice seems to be poor, highlighting a key area for possible intervention. Cumulative UVR exposure - the key risk factor for development of primary cutaneous SCC - over a golfinglifetime is dependent on frequency of play in conditions conducive to high UVR exposure, hence the increased risk for professional golfers who travel to temperate climate golf locations over the world and therefore increase their UVR exposure. The association between excessive UVR exposure and skin cancer is well documented, but the level of harm caused by UVR to the skin of a golfer is not only influenced by dose absorbed, but also skin type, number of melanonaevi, medical history and family history [19]. 'Outdoor workers', professional golfers, caddies and green keepers undoubtedly carry an increased risk of skin cancer 
Table 2. Considerations

Considerations for golfers

Considerations for the golfing industry
- Avoid sunburn (especially children, adolescents and those with other risk factors for skin cancer) [1,22]

- Individuals should recognise their skin type and what levels of UV exposure lead to sunburn $[1,12,18]$.

- Where possible, those with fair skin should play outwith times when the most harmful UVB radiation levels are highest (approx. 11am - 3pm depending on latitude) $[7,11]$.

- Golfers should be prepared for all weather eventualities and conscious of UV exposure in cloudy or shaded conditions $[11,12]$

- A wide-brimmed hat, clothing and sunglasses provide the most effective protection against UVR and should be used in combination with sunscreen on uncovered sites $[9,14]$.

- Sunscreen should be SPF 30 or above with five star UVA protection rating and applied liberally and regularly (every 2-3 hours) especially if sweating.

- The back of neck and ears are particularly susceptible to solar damage and should not be forgotten when selecting clothing and applying sunscreen $[9,10,12]$.

- Golfers should be aware of their increased risk of skin cancer and know how to identify the common forms of the disease, seeking medical attention early.

- Golf clubs may look after their members and staff by stocking photo-protective products and displaying golf-orientated health promotion material and advice on detecting skin cancer early [16].

- To promote the use of active sun protection [16].

- To increase public messaging for players and spectators on the potential risks of excessive UVR exposure.

- To consider using an influential public figure to aid health promotion through campaigns. through high UVR exposures [20,21], though this has not been proven with large-scale epidemiological studies in these specific groups. Recreational players probably have an overall lower risk than professionals. Golf can therefore pose an individual at risk, highlighting a key area for public health targeting and awareness needed. It has been seen from the qualitative studies that many golfers have little awareness on their risk of harmful UVR exposure, and simple educational awareness raising measures can have the potential to have a large public health impact on skin health.

There are currently no studies examining the morbidity and mortality associated with skin cancer in a golfing population, however overall, playing golf is associated with longevity, and physical health benefits [5]. The best understood beneficial effect of UVR is the synthesis of vitamin-D. Vitamin-D production requires exposure to UVB radiation, which causes sunburn and is more carcinogenic than UVA. It has been consistently shown that vitamin $\mathrm{D}$ can be efficiently and sufficiently produced at doses of UVB below those which cause sunburn in most people; and that prolonged exposure provides no additional vitamin D but linearly increases levels of DNA damage and risk of skin cancer. Thus, over-exposure to UVR resulting in sunburn and heavy tanning cannot be justified [22]. There is emerging evidence that sunshine has major health benefits independent of Vitamin-D but the mechanisms and impact require further research [3,23].

In summary, playing golf should be encouraged in all age groups due to overall health and well-being benefits, while golfers, the golf industry and policy makers should act to minimise harmful effects of UV radiation. As golf is played worldwide and in all seasons by a whole mix of skin types, potential harm from UV radiation will vary from player to player. The studies examined in this paper, in addition to the general literature on sun protection [24] support the key 'golf orientated' health promotion messages outlined in Table 2.

Active sun protection will always be dependent on attitudes and subsequent behaviors, which can vary widely. Therefore, in addition to striving to be as safe as possible in the sunshine, golfers should also be aware of their risk of skin cancer and know how to identify the common forms of the disease, seeking medical attention early. In view of their high level of occupational UVR exposure, professional golfers, caddies and golf industry workers are likely to benefit from targeted health promotion and skin cancer screening. This is an area that the golfing industry would be able to have a significant positive impact on through education, awareness and publication.

\section{CONCLUSIONS}

Overall, playing golf is associated with longevity, and both physical and mental health benefits. However, by being placed in the sun for extended periods of time, the golfing population faces an increased risk of UVR associated skin problems, most importantly skin cancer. Studies to date indicate that golfers are definitely exposed to potentially harmful levels of UVR during play and outdoor practice, but the morbidity/mortality related to this exposure is not known. More large-scale epidemiological studies are required to determine the true risk to skin health from playing golf (both professionally and recreationally) and the effectiveness of active sun protection and targeted health promotion at modifying outcomes in this group. Meantime, golfers are encouraged to take the sensible steps outlined in this paper to reduce their level of UV exposure during play. Golf facilities and the golf industry should take an active role in supporting golfers to reduce their level of UV exposure and empower them to be able to detect skin cancer early.

\section{Conflicts of Interest}

The authors declare no conflict of interest. 


\section{REFERENCES}

1. Lucas R, McMichael T, Smith W, Armstrong B. Solar ultraviolet radiation: global burden of disease from ultraviolet radiation. Environ Burden of Disease Series. 2006; 13:205

2. Theodoratou E, Tzoulaki I, Zgaga L, Ioannidis JP. Vitamin D and multiple health outcomes: umbrella review of systematic reviews and meta-analyses of observational studies and randomised trials. BMJ. 2014; 348: g2035.

3. Weller RB. Sunlight has cardiovascular benefits independently of vitamin D. Blood Purif. 2016; 41:130-134

4. Mead MN. Benefits of Sunlight: A Bright Spot for Human Health. Environ Health Perspect. 2008; 116(4):A160-A167.

5. Murray A, Daines L, Archibald, D et al. The relationships between golf and health: a scoping review. Br J Sports Med. 2017; 51(1):12-19.

6. Murray AD, Daines L, Archibald D et al. Infographic. Golf and Health. Br J Sports Med. 2017; 51(1):20-21.

7. Holman C, Gibson I, Stephenson M, Armstrong B. Ultraviolet irradiation of human body sites in relation to occupation and outdoor activity: Field studies using personal UVR dosimeters. Clin Exp Dermatol. 1983; 8(3):269-277.

8. Herlihy E, Gies P, Roy C, Jones M. Personal dosimetry of solar UV radiation for different outdoor activities. Photochem Photobiol. 1994; 60(3):288-294.

9. Thieden E, Philipsen P, Sandby-Møller J, Wulf H. Sunburn related to UV radiation exposure, age, sex, occupation, and sunbed use based on time-stamped personal dosimetry and sun behavior diaries. Arch Dermatol. 2005; 141(4):482-488.

10. Sung H, Slocum A. UV Radiation Exposure to Body Sites of Golfers and Effects of Clothing. Fam Con Sci Res. 2006; 34(4):386-400

11. Downs N, Schouten P, Parisi A, Turner J. Measurements of the upper body ultraviolet exposure to golfers: non-melanoma skin cancer risk, and the potential benefits of exposure to sunlight. Photodermatol Photoimmunol Photomed. 2009; 25(6):317-324

12. Downs N, Parisi A, Schouten P. Basal and squamous cell carcinoma risks for golfers: An assessment of the influence of tee time for latitudes in the Northern and
Southern hemispheres. J Photochem Photobiol B. 2011; 105:98-105.

13. Ysasi G, Moreno J, Serrano M. Ultraviolet Erythematic Radiation Dose Received by Golfers in Winter, in Valencia. Photochem Photobiol. 2014; 90:1170-1173

14. Hanke CW, Zollinger TW, O'Brian JJ, Bianco L. Skin cancer in professional and amateur female golfers. Phys Sportsmed. 1985; 13(8):51-68

15. Dixon H, Lagerlund M, Spittal M, Hill D, Dobbinson S, Wakefield M. Use of sun-protective clothing at outdoor leisure settings from 1992 to 2002: serial cross-sectional observation survey. Cancer Epidemiol Biomarkers Prev. 2008; 17(2):428-434

16. Perry A, Bae C, Nguyen L. Impact of sun safety education and skin cancer screening campaign on attendees of national sporting events. J Am Acad of Dermatol. 2010; 62(3):AB65

17. del Boz J, Fernández-Morano T, Padilla-España L, Aguilar-Bernier M, Rivas-Ruiz F, de Troya-Martín M. Skin cancer prevention and detection campaign at golf courses on Spain's Costa del Sol. Actas Dermosifiliogr. 2015; 106(1):51-60

18. Diffey B. Human exposure to solar ultraviolet radiation. J Cosmet Dermatol. 2002;1(3):124-30.

19. Gloster H, Brodland D. The epidemiology of skin cancer. Dermatol Surg. 1996; 22(3):217-226.

20. Glanz K, Buller D, Saraiya. Reducing ultraviolet radiation exposure among outdoor workers: State of the evidence and recommendations. Environ Health. 2007; $6: 22$

21. International Commission on Non-Ionizing Radiation Protection. ICNIRP Statement--Protection of Workers Against Ultraviolet Radiation. Health Phys. 2010; 99(1):66-87

22. Webb A, Kift R, Berry J, Rhodes L. The Vitamin D debate: Translating controlled experiments into reality for human sun exposure times. Photochem Photobiol. 2011; 87:741-745.

23. Glaser R, Naser F, Schuller W et al. UVB radiation induces the expression of antimicrobial peptides in human keratinocytes in vivo and in vitro. J Allergy Clin Immunol. 2009; 123:1117-1123

24. Janda M, Green A. Primary prevention of skin cancer. In: Evidence-Based Dermatology. 2014; 3:223-230. 